\title{
Efficacy of Bladder Ultrasound in Prediction of Resolution of Vesicoureteral Reflux after Endoscopic Subureteral Hyaluronic Acid/Dextranome (Deflux®) Injection
}

Hamdy Aboutaleb ( $\sim$ hamdyabotaleb@yahoo.com )

Menoufia University Hospital, Egypt and Burjeel Hospital, Abu Dhabi, UAE

Diaa Eldib

Benha University Faculty of Medicine

Mohamed Omar

Menoufia University Faculty of Medicine

Mohamed El Gharbawy

Menoufia University Faculty of Medicine

Fouad Zanaty

Menoufia University Faculty of Medicine

\section{Research article}

Keywords: Vesicoureteric reflux, Deflux, Urinary Bladder, ultrasound

Posted Date: January 20th, 2021

DOI: https://doi.org/10.21203/rs.3.rs-150283/v1

License: (c) (i) This work is licensed under a Creative Commons Attribution 4.0 International License. Read Full License

Version of Record: A version of this preprint was published at Urology on January 1st, 2022. See the published version at https://doi.org/10.1016/j.urology.2022.01.015. 


\section{Abstract}

BACKGROUND: We evaluated the efficacy of bladder ultrasound to predict resolution of vesicoureteral reflux after subureteral endoscopic Hyaluronic acid/dextranome (Deflux) injection.

METHODS: Between 2010 and 2018, 120 patients (220 ureters) underwent Subureteral Deflux injection for reflux in children. Male/female ratio was 1: 5 . All patients had voiding cystourethrography and bladder ultrasound at 3 months and one year after surgery. Outcome analysis included: Success rates and presence/ absence of Deflux mount by bladder ultrasound.

RESULTS: Mean follow-up was 48 months. Mean age at surgery 72 months. Grades of reflux were grade II in 100 ureters (45.4\%), III in 90 ureters (41\%) and IV-V in 30 ureters (13.6\%). Bilateral surgery was performed in 40 patients. Single Deflux injection cured reflux (Success rate) in $85 \%$ (187 ureters) at 3 months which improved to $88.2 \%$ (194 ureters) at last follow-up. Ultrasound was able to detect Deflux mounts at the base of the bladder in 200 ureters (91\%). Sensitivity and specificity of ultrasound was $92.68 \%$ and $20 \%$ of the correction of reflux at the last follow up. Positive Predictive Value of bladder ultrasound was $94 \%$ and accuracy was $87.7 \%$ at the last follow up. Ultrasound did not detect the mount in 20 ureters $(9 \%)$ and 8 of these ureters $(3.6 \%)$ had persistence of their reflux. Ultrasound was able to detect bilateral mounts as well as unilateral mounts.

CONCLUSION: Bladder-US was highly sensitive for detection of Deflux implants and can predict resolution of reflux in $82.7 \%$ of refluxing ureters. Postoperative bladder-US could be adjusted as a screening tool in the follow-up of patients with primary low-grade VUR patients treated by Deflux injection, while VCUG could be preserved for follow-up of high-grade VUR patients.

\section{Background}

Vesicoureteral reflux (VUR) represents the most common pediatric anomaly of the urinary tract, with increased risk of pyelonephritis and subsequent renal scarring. [1] [2] It affects about 1-3\% of all children. [3, 4] It can be managed using the widely known, minimally invasive procedure of endoscopic injection of hyaluronic acid/dextranome (Deflux). The Deflux injection is considered the first-line surgical intervention for effective VUR correction. [5] [6]

Voiding cystourethrography (VCUG) is the diagnostic examination of choice for pediatric patients with suspected VUR or follow-up of patients after surgical intervention. However, it is associated with the risk of radiation exposure in pediatric patients. The fluoroscopy time and the number of radiographs taken during the procedure vary between institutions depending on the operator's preference and experience. [7] [8]

Bladder ultrasound (US) is another technique that can be used to diagnose and follow-up VUR in pediatric patients. Its advantages include its wide availability, absence of radiation exposure, and easy reproducibility without the need for high-quality US scanners. [9] [10] Thus, the present study aims to 
determine the efficacy of bladder US in the detection of subureteral implants after endoscopic (Deflux®) injection. It also investigates whether US can be used as a substitute for VCUG so that radiation exposure can be minimized in pediatric patients.

\section{Methods}

Between 2010 and 2018, we retrospectively reviewed the files of 160 children (220 ureters) who were administered subureteral Deflux injection for VUR. Outcome analysis included success rates and the presence/absence of Deflux mound by bladder US. The research ethics board at Menoufia university hospital approved the study protocol with number 21/113. The parents of each selected pediatric patient signed an informed consent form before inclusion in the study. Exclusion criteria included patients with cloacal anomaly, neurogenic bladder, posterior urethral valve, previous open anti-refluxing surgery, ureteric abnormalities such as duplication, ureterocele, and diverticulum or those patients who had not complied with scheduled follow-ups and repeated Deflux injections.

According to the International Reflux Study committee classification [11], our patients with VUR were defined as grades I to V (Fig. 1). Based on the patient classifications used in previous studies, we also classified our patients into two groups: low-grade reflux (grades I to III) and high-grade reflux (grades IV and V). [12] [13] Briefly, Deflux injection was administered under general anesthesia as an outpatient procedure, using a pediatric straight working channel cystoscope with a minimum 4 French working channels. The Deflux metal needle $(3.7 \mathrm{~F} \times 23 \mathrm{G}$ tip $\times 350 \mathrm{~mm})$ was used to inject subureteral Deflux at 6 o'clock position inferomedially, and the needle was held for 30 seconds before withdrawal (Fig. 2). About 0.5 to $1.3 \mathrm{ml}$ Deflux was injected to obtain a well-formed mound of the injected material and a slit-like appearance of the ureteral orifice. Postoperatively, it was not necessary to leave an indwelling catheter. Patients were discharged from hospital on the same day of surgery with postoperative analgesia. The procedure was performed as described in published studies. [14] [15]

All patients had postoperative follow-ups, which included U/S-KUB and VCUG at three months and one year after surgery. Resolution of VUR was defined as the disappearance of VUR on VCUG images. If reflux persisted, the VCUG was repeated after one year. The same team of radiologists also performed bladder US. The radiologists were blinded to the VCUG results but informed about the interest for detection of Deflux implants at the base of the urinary bladder. Outcome analysis included success rates and presence/absence of Deflux mound by bladder US which performed using Samsung RS80A with multifrequency transducers (7.5 MHz linear or $3.5 \mathrm{MHz}$ convex transducers, depending on the patient's age). The bladder base and ureterovesical junctions were evaluated in at least two anatomic planes. Any solid oval-shaped structure at or around the ureterovesical junction with an echogenicity equal to or slightly greater than that of bladder wall, was accepted as the Deflux mound (Fig. 3). The examination was performed as described in published study by Özcan et al. [16]

All descriptive data are shown as means and standard deviation (SD), median or numbers (\%). Performance characteristics were calculated as follows: sensitivity $=($ true positive $) /($ true positive + false 
negative); specificity = (true negative) $/($ true negative + false positive); positive predictive value $(\mathrm{PPV})=$ (true positive)/(true positive + false positive); negative predictive value (NPV) $=$ (true negative) $/($ false negative + true negative); accuracy $=($ true positive + true negative $) /($ true positive + false negative + true negative + false positive).

\section{Results}

Overall, subureteral injection of Deflux was administered in 160 patients who had primary VUR (220 ureters). Male to female ratio was 1:3 (40 males (25\%) and 120 females $(75 \%))$, and the mean age at surgery was 72 months (range 24-180 months). Bilateral surgery was performed in 60 patients (37.5\%), while unilateral surgery was performed in 100 patients $(62.5 \%)$. The mean age of the patients was 5.4 years (range from 6 months to 10 years).

The mode of presentation was recurrent urinary tract infections in 102 (63.7\%) patients, antenatal hydronephrosis in $48(30 \%)$ and incidental in $10(6.25 \%)$ patients. With respect to grades of reflux, grade II reflux was observed in 100 patients (45.4\%), grade III in 90 patients (41\%), and grades IV-V were observed in 30 patients (13.6\%). In all 220 ureters, a single Deflux injection cured reflux in 85\% (187/220 ureters) at three months and $88.2 \%$ (194/220 ureters) at last follow-up. Second Deflux injections are not included in this study.

In low-grade VUR (grades II \& III) (190 ureters), Deflux injection cured reflux in $94.7 \%$ at first follow-up and $98 \%$ at last follow-up. In high-grade VUR (grades IV \& V) (30 ureters), Deflux injection cured reflux in $23.3 \%$ at first follow-up and $26.6 \%$ at last follow-up (Table 1). Bladder US detected Deflux mounds in 200 ureters (91\%). Of them, $79.5 \%$ showed corrected VUR at 3 months follow-up and $76.4 \%$ at last follow up. Deflux mounds were detected in 25 ureters (11.4\%) at three months follow-up, and 12 ureters (5.4\%) at last follow-up in patients with persistent VUR. Bladder US could not detect the mound in 20 ureters (9\%) at first follow-up; 12 (5.4\%) of these ureters had corrected reflux and 8 ureters $(3.6 \%)$ had persistent reflux. At last follow-up, the Deflux mounds were not detected in 40 ureters (18\%); $26(11.8 \%)$ of these ureters had corrected reflux and 14 ureters (6.4\%) had persistent reflux (Table 2). 
Table 1

Success rates of Deflux injection in low and high grades VUR

\begin{tabular}{|c|c|c|c|c|c|}
\hline & & \multicolumn{4}{|c|}{ Grades of VUR } \\
\hline & & \multicolumn{2}{|c|}{ Low-grade VUR } & \multirow{2}{*}{$\begin{array}{l}\text { High-grade } \\
\text { VUR } \\
\text { IV-V }\end{array}$} & \multirow[t]{2}{*}{ Total } \\
\hline & & II & III & & \\
\hline \multirow[t]{4}{*}{$\begin{array}{l}\text { Success rate of Deflux } \\
\text { injection }\end{array}$} & $\begin{array}{l}\text { First } \\
\text { follow-up }\end{array}$ & $\begin{array}{l}96 / 100 \\
(96 \%)\end{array}$ & $\begin{array}{l}84 / 90 \\
(93.3 \%)\end{array}$ & \multirow[t]{2}{*}{$\begin{array}{l}7 / 30 \\
(23.3 \%)\end{array}$} & \multirow[t]{2}{*}{$\begin{array}{l}187 / 220 \\
(85 \%)\end{array}$} \\
\hline & & \multicolumn{2}{|c|}{ 180/190 (94.7\%) } & & \\
\hline & $\begin{array}{l}\text { Last } \\
\text { follow-up }\end{array}$ & $\begin{array}{l}99 / 100 \\
(99 \%)\end{array}$ & $\begin{array}{l}87 / 90 \\
(96.6 \%)\end{array}$ & \multirow[t]{2}{*}{$\begin{array}{l}8 / 30 \\
(26.6 \%)\end{array}$} & \multirow[t]{2}{*}{$\begin{array}{l}194 / 220 \\
(88.2 \%)\end{array}$} \\
\hline & & \multicolumn{2}{|c|}{$186 / 190(98 \%)$} & & \\
\hline
\end{tabular}

VUR: Vesicoureteral reflux.

Table 2

Correlation between Deflux implants detection and VUR correction.

\begin{tabular}{|c|c|c|c|c|}
\hline & & Visible mount & Absent mount & Total \\
\hline \multirow{4}{*}{$\begin{array}{l}\text { Corrected VUR } \\
\text { (No. of Ureters) }\end{array}$} & First follow-up & 175 & 12 & 187 \\
\hline & & (79.5\%) & $(5.4 \%)$ & $(85 \%)$ \\
\hline & Last follow-up & 168 & 26 & 194 \\
\hline & & (76.4\%) & $(11.8 \%)$ & $(88.2 \%)$ \\
\hline \multirow{4}{*}{$\begin{array}{l}\text { Persistent VUR } \\
\text { (No. of Ureters) }\end{array}$} & First follow-up & 25 & 8 & 33 \\
\hline & & (11.4\%) & (3.6\%) & $(15 \%)$ \\
\hline & Last follow-up & 12 & 14 & 26 \\
\hline & & $(5.4 \%)$ & $(6.4 \%)$ & (11.8\%) \\
\hline \multirow[t]{2}{*}{ Total } & First follow-up & 200 (91\%) & $20(9 \%)$ & 220 (100\%) \\
\hline & Last follow-up & $180(82 \%)$ & $40(18 \%)$ & $220(100 \%)$ \\
\hline
\end{tabular}

VUR: Vesicoureteral reflux.

At first follow-up, the sensitivity of bladder US in predicting complete VUR resolution was $93.6 \%$ for VUR correction, specificity was $24 \%$, positive predictive value was $87.5 \%$, negative predictive value was $40 \%$ and accuracy was $83 \%$. At last follow-up, sensitivity of bladder US in predicting complete VUR resolution was $86.6 \%$ for VUR correction, specificity was $54 \%$, positive predictive value was $93 \%$, negative predictive value was $35 \%$ and accuracy was $83 \%$ (Table 3 ). Persistent reflux was observed in 33 units (15\%) at 3 
months (first) follow-up that decreased to 26 units (11.8\%) at last follow-up and denovo hydronephrosis in 8 units (3.6\%) that were resolved spontaneously. None of the patients had contralateral reflux.

Table 3

Sensitivity, Specificity, PPV, NPV \& Accuracy of bladder US in diagnosing success rate of VUR.

\begin{tabular}{|lll|}
\hline & First follow-up & Last follow-up \\
\hline Sensitivity (\%) & 93.6 & 86.6 \\
\hline Specificity (\%) & 24 & 54 \\
PPV (\%) & 87.5 & 93 \\
\hline NPV (\%) & 40 & 35 \\
\hline Accuracy (\%) & 83 & 83 \\
\hline PPV: Positive predictive value. & NPV: Negative predictive value. \\
\hline
\end{tabular}

\section{Discussion}

Although VCUG and radionuclide cystography are presently the examinations of choice for the evaluation of VUR, radiation exposure from both these techniques is still a cause of worry. Also, there is other disadvantages of radioisotope cystography include bladder catheterization, poor anatomical details of the urethra, and vesicoureteric junction. So, every effort should be made towards minimization of radiation exposure during evaluation of VUR in infants and children. In this regard, US is the most advantageous alternative because it is a safe, simple, and widely accessible modality with no radiation exposure to rule out residual hydronephrosis and examine the Deflux injection site. [16] [17]

In our study, US detected Deflux mounds at the base of the urinary bladder in 200 ureters (91\%) with sensitivity of implant visualization on bladder US in predicting complete VUR resolution on postoperative VCUG $86.6 \%$, specificity $54 \%$, PPV $93 \%$, NPV $35 \%$, and accuracy $83 \%$ at last follow-up. Park et al [18] studied 56 ureters ( 36 children) and found Deflux mounds on bladder US in 38 ureters $(68 \%)$. The sensitivity was $73 \%$, specificity was $44 \%$, PPV was $76 \%$, and NPV was $39 \%$. In comparison, our study showed higher sensitivity, specificity and PPV; this may be explained by the comparatively higher number of patients included in our study. NPV was found to be similar to that reported in their study.

Lee et al [19] examined 149 patients (220 ureters), and of them, 122 patients (82\%) were injected with Deflux and 27 patients (18\%) were injected with polydimethylsiloxane (Macroplastique). Bladder US detected injection implants in 152 ureters (69\%). VUR was cured in 128 ureters (84\%). The success rate in visualized injection implants group was $84.2 \%$, while that in absent injection implants group was $48.5 \%$. Bladder US had $79.5 \%$ sensitivity, 59\% specificity, $84 \%$ PPV, $51.5 \%$ NPV, and $74 \%$ accuracy as a diagnostic tool for successful correction of VUR. Injection implants were detected by US in only $69 \%$ ureters 
compared to $91 \%$ ureters in our study. This may be explained by the use of Macroplastique and Deflux injections in their study, while all patients in our study were administered Deflux injections only. Also, US is an operator-dependent modality, and the results may differ depending on the operator or the machine used in the examination.

In our study, the number of US identified Deflux implants decreased from $91 \%$ at first follow-up to $82 \%$ at last follow-up. This finding is in line with Özcan et al [16] study, who described reduced rates of US detection of implants during follow-up from $80 \%$ in the first postoperative month to $45 \%$ at a mean follow-up of 2.2 years. He suggested that reduction in implant volume could be due to the replacement of dextranomer particles by collagen.

In our study, Bladder US could not detect Deflux mounds in 20 ureters (9\%) at first follow-up; 12 (5.4\%) of these ureters had corrected reflux and 8 ureters $(3.6 \%)$ had persistent reflux. At last follow-up, the Deflux mounds were not detected in 40 ureters (18\%); $26(11.8 \%)$ of these ureters had corrected reflux and 14 ureters $(6.4 \%)$ had persistent reflux. Our study showed low specificity and NPV for the identification of Deflux implant on bladder US and prediction of VUR resolution. So, the non-visualized Deflux implant could not be diagnostic option of persistent VUR. This finding has also been described in previous reports. Park et al stated that low specificity of non-visualized implants on bladder US for persistent VUR could be explained by ureteral orifice anti-reflux mechanism caused by tissue expansion resulting from endogenous collagen between microspheres. [18] Lee et al and Yucel et al attributed this to treatment-associated factors such as surgeon skills, injection technique, injection mound location, injectable volume, US machines used, and operator-dependent factors. [19] [20]

Also our study is in line with Park et al [18] findings that stated VCUG may not be necessary if bladder US identified Deflux implants in the correct position and of good size. VCUG could be indicated when the implant is not identified on bladder US or is of small size.

Our study concluded that, Deflux injection cured reflux in $98 \%$ of ureters in low-grade VUR and $26.6 \%$ of ureters with high-grade reflux at last follow-up. Thus, postoperative US could be adjusted as a screening examination in the follow up of children treated for low grade VUR and can select patients with high grade VUR who will require subsequent VCUG to exclude persistent VUR especially if the implant is not clearly visualized and not has good volume. Our protocol was thus modified in the last few years to using US only at the follow-up of low-grade cases. Limitations of the present study include possible sampling bias due to retrospective nature of the study. Also, validation of the sonographic appearance and volume of the implant as a prognostic factor for treatment success in low-grade VUR cases may be necessary.

\section{Conclusion}

Hyaluronic acid/dextranome (Deflux) offers a simple minimally invasive endoscopic procedure with high success rates for primary VUR. Bladder-US was highly sensitive for detection of Deflux implants and can predict resolution of reflux in $82.7 \%$ of refluxing ureters. Postoperative bladder-US could be adjusted as a 
screening tool in the follow-up of patients with primary low-grade VUR patients treated by Deflux injection, while VCUG could be preserved for follow-up of high-grade VUR patients.

\section{Abbreviations}

- US: Ultrasound

- VCUG: Voiding cystourethrography

- VUR: Vesicoureteral reflux

- KUB-US: Kidney-Urinary Bladder Ultrasound

- PPV: Positive predictive value

- NPV: Negative predictive value

\section{Declarations}

\section{- Ethics approval and consent to participate:}

All procedures performed in this study were in accordance with the ethical standards of the Institution and/or National Research Committee and with the 1964 Declaration of Helsinki and its later amendments or comparable ethical standards.

\section{- Consent for publication:}

Not applicable

\section{- Availability of data and material:}

They are available on request

- Competing interests:

The authors declare that they have no competing interests.

- Funding:

Not applicable

- Authors' contributions: 
$\mathrm{HA}$ and $\mathrm{FZ}$ wrote the manuscript, performed the operation, and managed the patient's perioperative course. FZ gave the final approval of this manuscript. DE reviwed the images and follow up patients with US and VCUG. ME and MK read and approved the final manuscript.All authors have read and approved the manuscript.

\section{- Acknowledgements:}

The abstract is presented in UAA 2020 in Seoul and published at International Journal of Urology, which can be found at: https://onlinelibrary.wiley.com/doi/10.1111/iju.14397

\section{References}

1. Kim, S.W., Y.S. Lee, and S.W. Han, Endoscopic injection therapy. Investig Clin Urol, 2017. 58(Suppl 1): p. S38-S45.

2. Smellie, J.M., et al., Outcome at 10 years of severe vesicoureteric reflux managed medically: Report of the International Reflux Study in Children. J Pediatr, 2001. 139(5): p. 656-63.

3. Cooper, C.S., Diagnosis and management of vesicoureteral reflux in children. Nat Rev Urol, 2009. 6(9): p. 481-9.

4. Shim, J.S., et al., Efficacy of hydrodistention implantation technique in treating high-grade vesicoureteral reflux. Korean J Urol, 2012. 53(3): p. 194-9.

5. Jodal, U., et al., Ten-year results of randomized treatment of children with severe vesicoureteral reflux. Final report of the International Reflux Study in Children. Pediatr Nephrol, 2006. 21(6): p. 785-92.

6. Hidas, G., et al., Is the appearance of the dextranomer/hyaluronic acid mound predictive of reflux resolution? J Urol, 2013. 189(5): p. 1882-5.

7. Lee, R.S., D.A. Diamond, and J.S. Chow, Applying the ALARA concept to the evaluation of vesicoureteric reflux. Pediatr Radiol, 2006. 36 Suppl 2: p. 185-91.

8. Ward, V.L., et al., Pediatric radiation exposure and effective dose reduction during voiding cystourethrography. Radiology, 2008. 249(3): p. 1002-9.

9. Darge, K., Diagnosis of vesicoureteral reflux with ultrasonography. Pediatr Nephrol, 2002. 17(1): p. $52-60$.

10. Xhepa, R., M. Bosio, and G. Manzoni, Voiding cystourethrosonography for the diagnosis of vesicoureteral reflux in a developing country. Pediatr Nephrol, 2004. 19(6): p. 638-43.

11. Lebowitz, R.L., et al., International system of radiographic grading of vesicoureteric reflux. International Reflux Study in Children. Pediatr Radiol, 1985. 15(2): p. 105-9.

12. Schaeffer, A.J., et al., Reliability of grading of vesicoureteral reflux and other findings on voiding cystourethrography. J Pediatr Urol, 2017. 13(2): p. 192-198.

13. Roussey-Kesler, G., et al., Antibiotic prophylaxis for the prevention of recurrent urinary tract infection in children with low grade vesicoureteral reflux: results from a prospective randomized study. J Urol, 
2008. 179(2): p. 674-9; discussion 679.

14. Kim, S.O., et al., Clinical efficacy and safety in children with vesicoureteral reflux of a single injection of two different bulking agents-polydimethylsiloxane (Macroplastique) or dextranomer/hyaluronic acid copolymer (Deflux): a short-term prospective comparative study. Urol Int, 2011. 87(3): p. 299303.

15. Ure, I., et al., Subureteral Injection with Small-Size Dextranomer/Hyaluronic Acid Copolymer: Is It Really Efficient? Biomed Res Int, 2016. 2016: p. 2168753.

16. Ozcan, C., et al., Bladder ultrasound in the evaluation of the efficacy of dextranomer/hyaluronic acid injection for treatment of vesicoureteral reflux. J Clin Ultrasound, 2007. 35(7): p. 357-62.

17. Silay, M.S., et al., Imaging for Vesicoureteral Reflux and Ureteropelvic Junction Obstruction. Eur Urol Focus, 2016. 2(2): p. 130-138.

18. Park, K.J., et al., The appearance of dextranomer-hyaluronic acid copolymer implants on ultrasound may predict resolution of vesicoureteral reflux after injection therapy. Clin Radiol, 2014. 69(9): p. 93944.

19. Lee, D.G., et al., Significance of an endoscopically injected nodule detected on ultrasound as a predictive factor for the resolution of vesicoureteral reflux. Exp Ther Med, 2015. 9(3): p. 1058-1062.

20. Yucel, S., A. Gupta, and W. Snodgrass, Multivariate analysis of factors predicting success with dextranomer/hyaluronic acid injection for vesicoureteral reflux. J Urol, 2007. 177(4): p. 1505-9.

\section{Figures}



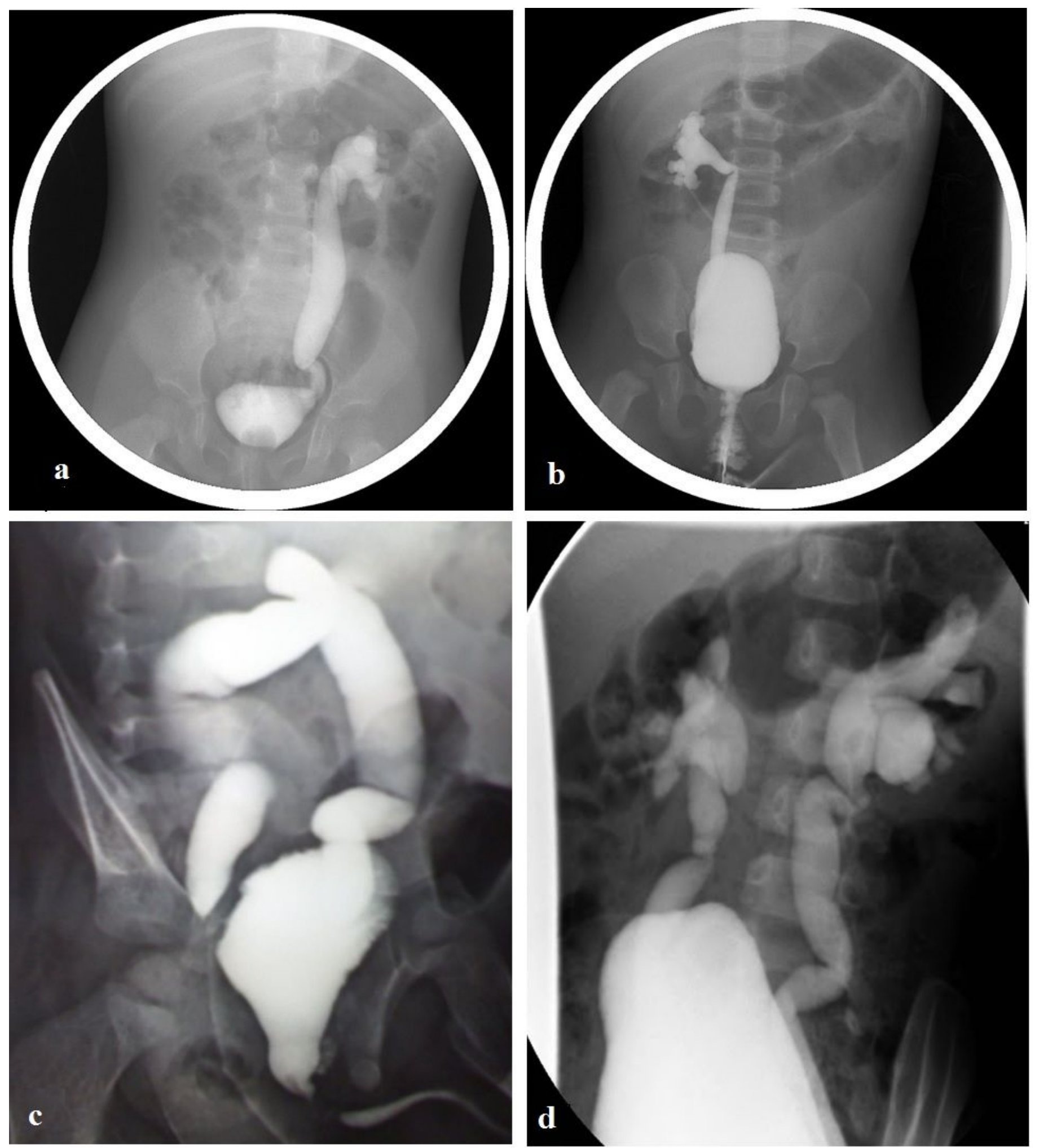

\section{Figure 1}

Grades of Vesicoureteral reflux. a: Left side grade III reflux, b: Right side grade II reflux, c \& d: Bilateral high grade reflux. 

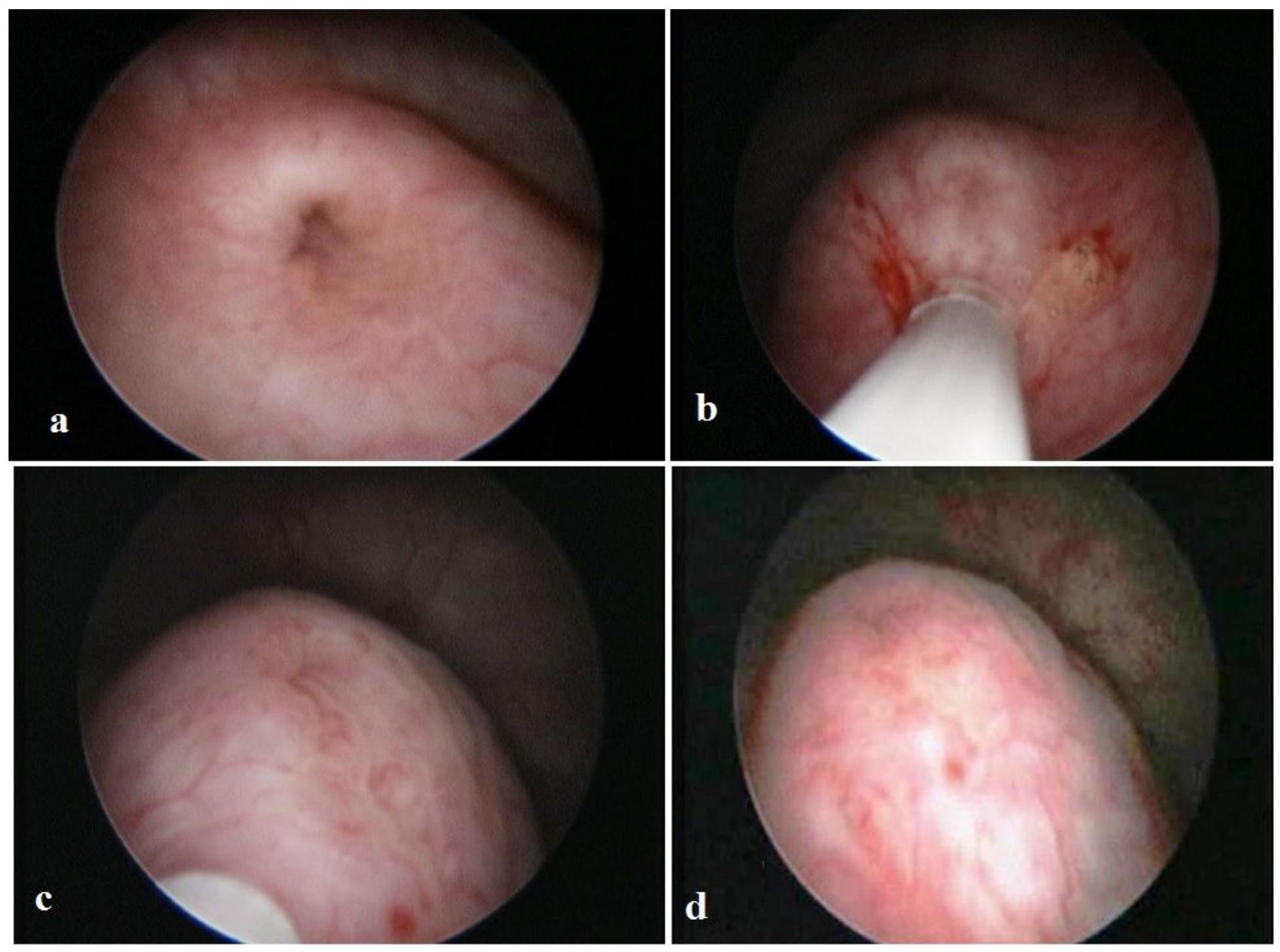

Figure 2

Pediatric cystoscopy with Subureteral Deflux injection at 6 o'clock position and a well-formed mound was obtained. 

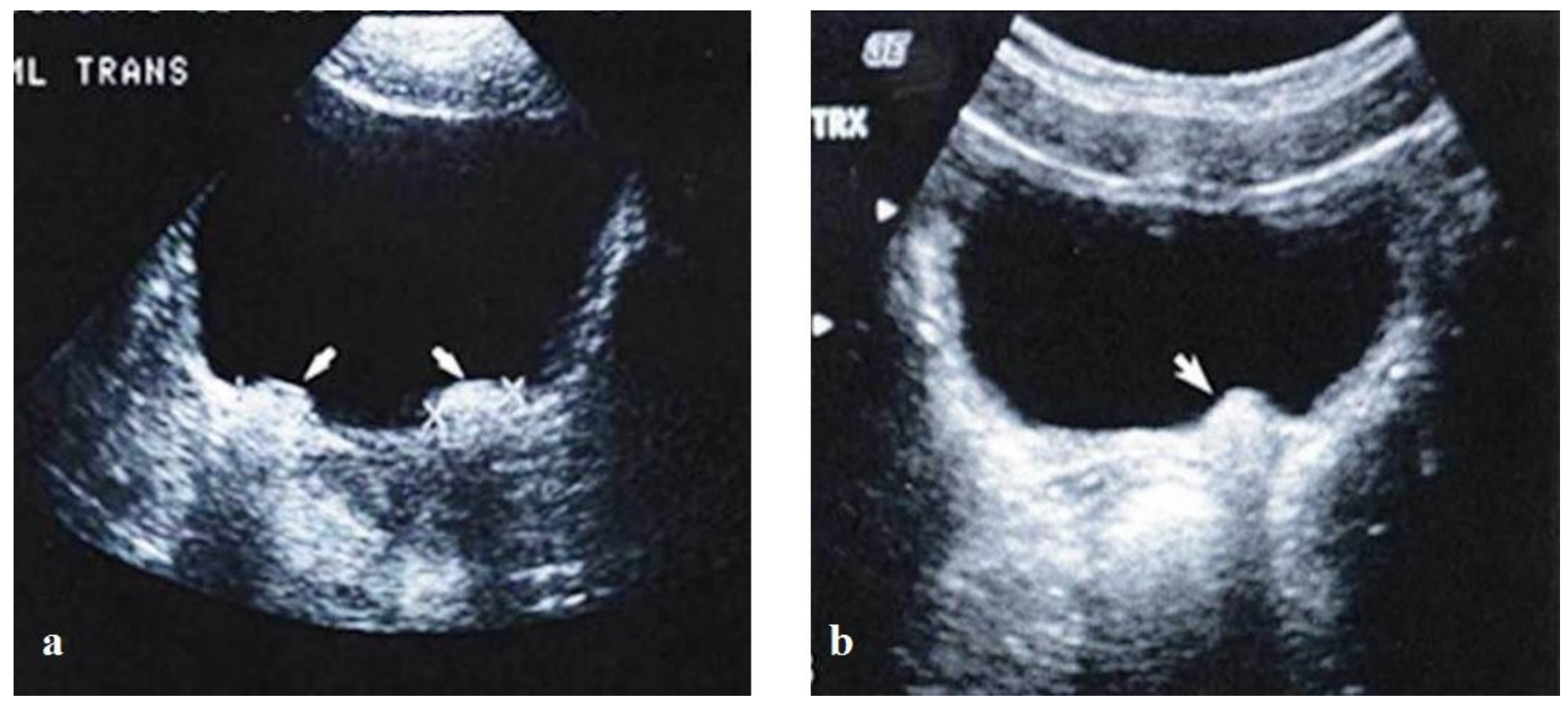

\section{Figure 3}

Bladder Ultrasound showing Deflux mound at the base of the urinary bladder a: Bilateral sides, b: Unilateral left side. 